\title{
From terroir to pangkarra: Geographical indications of origin and Indigenous knowledge*
}

\author{
Brad Sherman \& Leanne Wiseman
}

There has been a marked increase over the last few decades or so in the number of countries which recognise and protect geographical indications of origin. There has also been a steady expansion in the types of things that are protected. While this is not that surprising given the growing interest in slow food and traditional products, ${ }^{1}$ what is more surprising, at least at first glance, is the increased attention that has been given to the potential use of geographical indications of origin to support and promote Indigenous interests. Geographical indications of origin have been associated with Indigenous traditional knowledge in two ways. Firstly, it has been suggested that geographical indications of origin could be used as a mechanism to protect and sustain indigenous interests. ${ }^{2}$ This is because, as the WIPO Intergovernmental Committee on Intellectual Property and Genetic Resources, Traditional Knowledge and Folklore noted, some traditional cultural expressions may qualify as goods which could be protected by geographical indications. ${ }^{3}$ Secondly, and more ambitiously, it has also been suggested that the regimes used to regulate geographical indications might be used as a template on which sui generis schemes to protect Indigenous knowledge might be modelled.

\footnotetext{
* The Kauma people from the Adelaide Plains in South Australia use the term 'pangkarra' to describe the characteristics of a particular place and how it shapes things from that place. See Max Allen, 'Terroir Australia', The Weekend Australian Magazine (13 Dec 2003), 48. We would like to thank Dev Gangjee for his comments on the chapter.

1 On this see C. Bramley and J. Kirsten, 'Exploring the Economic Rationale for Protecting Geographical Indicators in Agriculture' (2007) 46(1) Agrekon 47; B. Ilbery and M. Kneafsey, 'Registering Regional speciality food and drink products in the United Kingdom: The case of PDO's and PGI's (2000) 32(3) Area 317; Elizabeth Barham, 'Translating terroir: the global challenge of French AOC Labeling' (2003) 19 Journal of Rural Studies 127; See also Barham's contribution in chapter XXX of this volume.

2 See Teshager Worku Dagne, 'Harnessing the development potential of geographical indications for traditional knowledge-based agricultural products' (2010) 5(6) Journal of Intellectual Property Law and Practice 441; Commission on Intellectual Property Rights, Integrating Intellectual Property Rights and Development Policy (2002), chapter 4; David Downes, 'How Intellectual Property Could be a Tool to protect traditional knowledge' (2000) 25 Columbia Journal of Environmental Law 253, 281: Ranjay K Singh, RC Srivastava, Adi Community, and Monpa Community, 'Biological geographical indicators of traditional knowledge based products and green technology from Arunachal Pradesh: An initiative for safeguarding IPR of Communities' (2010) 9(4) Indian Journal of Traditional Knowledge 689. Terri Janke, Minding Culture: Case Studies on Intellectual Property and Traditional Cultural Expression (Geneva, WIPO, 2003), 36 (given that indigenous peoples cultural expression reflects their belonging to land and territories, this may allow some scope for indigenous people to use geographic indications for their clan names, and language words for regions'). There are, however, critics. See, for example, Madhavi Sunder, 'IP3' (2006) 59 Stanford Law Review 257, 302; Shivani Singhal, 'Geographical Indications and traditional knowledge' (2008) 3(11) Journal of Intellectual Property Law and Practice 732, 738.

3 WIPO, 'Consolidated Analysis of the Legal Protection of Traditional Cultural Expressions', WIPO/GRTKF/IC/5/3, 52.
} 
It is the aim of this chapter to look at the suggestion that geographical indications of origin offer an effective and appropriate way of protecting Indigenous traditional knowledge. In particular, we ask: is it realistic to expect that geographical indications of origin can be used to protect Indigenous knowledge? While it is possible to imagine the law of geographical indications protecting aspects of traditional knowledge, we argue that beyond this it is unlikely that geographical indications would be ever be modified in a way that would allow Indigenous knowledge to be accommodated on its own terms.

There are a number of questions that need to be addressed before we are able to explore this issue in more detail: one of the most important being what do we mean by 'traditional knowledge' and 'geographical indication of origin'? This is especially important given the uncertainty that surrounds these broad terms ${ }^{4}$. In part these problems are made worse by the growing demand, which has been prompted by the push for international protection, for globally relevant definitions that can be applied equally in Switzerland and Sudan. This is particularly the case with the term 'traditional knowledge' which has found favour at the international level and amongst intellectual property scholars. While WIPO's decision to pursue a top-down international treaty to regulate traditional knowledge means that a broad-based definition of traditional knowledge is almost inevitable, for others, however, the attempt to develop a functional, universal definition is a folly, not least because 'the term traditional knowledge is so broad that any attempt to define it is necessarily incomplete. ${ }^{5}$ This concern is borne out by experience in Australia, where the decision as to whether a person is classified as 'Aboriginal' or 'Torres Strait Islander' has, at times, been controversial and problematic. Questions such as who decides whether a person is Indigenous and the criteria used to make this decision are not only highly politicised, they also carry significant cultural, social, spiritual, legal and economic consequences. These problems have been compounded by the fact that many Indigenous peoples have forcibly been removed from the country that forms such a strong connection to tradition. This is not to suggest that removal from country necessarily equates to a loss of tradition: so much as that the nature of the connection to country and, with it, what is meant by traditional knowledge changes; a change that makes the task of developing a global definition all

\footnotetext{
4 'Apart from politics, a main reason for deferring [discussions at the International level] at this stage is the fact that sufficiently clear concepts of scope and level of protection for TK and expanded GI's are still lacking'. Marion Panizzon, 'Traditional Knowledge and Geographical Indications: Foundations, Interests and negotiating positions' (Oct 2006) NCCR Trade Working Paper No 2005/01, 6.

5 Shivani Singhal, 'Geographical Indications and Traditional Knowledge' (2008) 3(11) Journal of Intellectual Property Law and Practice 732, 738.
} 
the more problematic. While we will, where possible, try to speak generally about Indigenous traditional knowledge, we will draw our examples from Australia.

There is also some uncertainty about what is meant by a 'geographical indication of origin'. In part this arises because there is no international consensus about the minimum standards for protection, nor about what the criteria for protection should be. Instead, there are a range of national and regional laws suited to local interests that have been used to regulate the name of products (and indirectly also the product itself) including geographical indications of origin, designations of origin, indications of source, and appellations of origin. The fact that the 'manner in which the protection of GIs has been conceptualised in different countries at different times has varied considerably' has created an ambiguity in basic terminology. ${ }^{6}$ It has also meant that with 'the exception of design law, there is probably no category of intellectual property law where there exists such a variety of concepts of protection as in the field on geographical indications. ${ }^{7}$ These problems are exacerbated by the fact that like many things today, geographical indications are 'no longer what they used to be'. ${ }^{8}$ This is particularly notable in Europe, which is the spiritual home of geographical indications of origin, where there has not only been a splintering in the types of protection, but also been a change in the standards for protection: the EC no longer requires that a product should be endowed with exclusive characteristics by its geographic origin in order to qualify for protection. ${ }^{?}$

While geographical indications take a number of different forms, it is possible to characterise them in terms of how the connection between the named product and its geographical origin is determined $^{10}$. At one extreme, some types of geographical indications of origin - which we will refer to as natural geographical indications of origin ${ }^{11}$ —are only granted where an applicant can show that the characteristics of the named product are a direct result of the place where the product

\footnotetext{
${ }^{6}$ Oskari Rovamo, 'Monopolising Names? The Protection of Geographical Indications in the European Community' (2006) Helsinki University, Pro Gradu Thesis, 5. See also Bernard O’Connor, The Law of Geographical Indications (2004), 23.

${ }^{7}$ S. Escudero, International Protection of geographical indications and developing countries Trade Working Paper 10, (South Centre, Geneva: 2001). As cited in C. Bramley and JF Kirsten, 'Exploring the Economic Rationale for Protecting Geographical Indicators in Agriculture' (2007) 46(1) Agrekon 47, 49.

8 Oskari Rovamo, 'Monopolising Names? The Protection of Geographical Indications in the European Community' (2006) Helsinki University, Pro Gradu Thesis, 5.

${ }^{9}$ This is reflected in the definition of a Geographical Indication, where a reputational link to the region of origin is sufficient. See Art 5(2) of Regulation (EU) No 1151/2012 on Quality Schemes for Agricultural Products and Foodstuffs.

10 While this distinction could also been seen in terms of stronger and weaker GIs, we wish to highlight the connection between product and the environment in which it is grown. Thus, instead of speaking of the relative level of protection, we wish to focus on the nature of the connection between nature and right.

${ }^{11}$ For an interesting account of the important role that natural geographical indications of origin play as ideal types and rhetorical device in the law see Dev Gangjee, Relocating the law of geographical indications (Cambridge 2012), 77-126.
} 
was produced or, as the Lisbon Agreement states, the 'quality and characteristics' of a product are 'due exclusively or essentially to the geographic environment, with its inherent natural and human factors ${ }^{\prime 12}$. From this perspective, a natural geographical indication is a form of collective intellectual property in which 'the protection is related to the product itself and is neither dependant on a specific right holder nor on consumer deception or confusion' ${ }^{13}$. For our purposes, the defining feature of this form of geographical indication of origin is the role that 'nature' plays in shaping the named product. At the other extreme, and in contrast to natural geographical indications, there are a range of geographical indications of origin which are much more dependent on consumer perceptions about the product in question and its competitors, rather than on the role that nature plays in shaping the product. While with this type of geographical indication there is a connection between product and place, the status of this connection is not something that needs to be proved as an end in itself: instead, what is important is the way that consumers view this connection. To avoid confusion, whenever we speak of geographical indications in this chapter we will refer to natural geographical indications of origin.

$* * *$

There are a number of similarities and points of connection between geographical indications of origin and Indigenous traditional knowledge. One of these relates to the way that geographical indications of origin and traditional knowledge are perceived. More specifically it arises because geographical indications of origin and traditional knowledge are both seen as outsiders - as maverick, sui generis, dangerous, ill-fitting, and different. While there has been a lot written about the image of Indigenous peoples as dangerous outsiders, ${ }^{14}$ there has been less consideration given to the status and standing of the laws that regulate geographical indications of origin. Despite this, however, it is clear that geographical indications of origin share many of the attributes that are often (pejoratively) associated with traditional knowledge. The outsider status of geographical indications is reflected, for example, in the debates about whether geographical indications of origin properly belong within intellectual property law and in their characterisation as a suigeneris form of protection ${ }^{15}$. The outsider status is also reflected in the fact that geographical indications of origin run against the grain of mainstream intellectual

12 Lisbon Agreement for the Protection of Appellations of Origin and their International Registration, s 2(1).

13 Oskari Rovamo, 'Monopolising Names? The Protection of Geographical Indications in the European Community' (2006) Helsinki University, Pro Gradu Thesis, 1-2.

14 See, eg, Amanda Nettelbeek and Robert Foster, In the Name of the Law (2007).

15 Stephen Stern 'Are GIs IP? (2007) 29 European Intellectual Property Review 39. See also D. Rangnekar, 'The Intellectual Properties of Geography’ (2009) 31 European Intellectual Property Review 537. 
property law. This can be seen, for example, in the remark that 'geographical indications as a form of intellectual property challenges the law, culture and economic logic of American business, orientated as it is towards liberal economic theory based in individual ownership ${ }^{16}$.

The outsider status of geographical indications is reinforced by the fact that while intellectual property law is often portrayed as modern and progressive, this is not the case with geographical indications of origin, which are seen to be pre-modern and traditional. While patents, design, and copyright are concerned with advancement, novelty, progress, and the protection of the new, in contrast geographical indications are more concerned with preserving and sustaining localised traditional (almost indigenous) practices. Moreover, while modern intellectual property law is seen to be abstract, agnostic, standardised and global, geographical indications, like the laws that regulate them, are still rooted in the local: they are parochial, judgemental, and disparate. Although neither of these caricatures stands up to scrutiny, nonetheless they still underpin the way that intellectual property law generally and geographical indications more specifically are often viewed.

For many this maverick status is a problem that needs to be rectified. For others, however, it is a cause for celebration in so far as it provides new ways of thinking about intellectual property law. To this end, we have recently seen a small but growing number of commentators who have turned to the law of geographical indications of origin on the basis that it offers an alternative (conceptual) framework for thinking through some of the issues facing intellectual property law $^{17}$. Geographical indications of origin are also being celebrated because they take account of broader social and cultural interests: which is one of the reasons for the growing interest in geographical indications of origin and traditional knowledge.

There are a number of other reasons why geographic indicators are seen to be 'especially suitable' for use by indigenous and local communities. ${ }^{18}$ In addition to the general economic

16 Elizabeth Barham, 'Translating terroir: the global challenge of French AOC Labeling' (2003) 19 Journal of Rural Studies 127, 129.

17 See, eg, Mario Biagioli, 'Nature and the Commons: The Vegetable Roots of Intellectual Property' in Jean-Paul Gaudilliere, Daniel J. Kevles, Hans-Jorg Rheinberger (eds.) Living Properties: Making Knowledge and Controlling Ownership in the History of Biology (Max Plank Institute for History of Science Preprint 382, 2009), 241-250; 'Rosemary Coombe, 'Cultural Agencies: "Constructing" Community Subjects and their Rights' in Peter Jaszi and Martha Woodmansee (eds.), Making and Unmaking Intellectual Property (Chicago University Press, Chicago 2011), 79.

18 David Downes, 'How Intellectual Property Could be a Tool to protect traditional knowledge' (2000) 25 Columbia Journal of Environmental Law 253, 269; Kal Raustiala and Stephen Munzer, 'The Global Struggle over Geographical Indications' (2007) 18(2) The European Journal of International Law 337, 345. ('GIs and traditional knowledge share several attributes'). C. Bramley and J.F. Kirsten, 'Exploring the Economic Rationale for Protecting Geographical Indicators in Agriculture’ (2007) 46(1) Agrekon 47. 
arguments made in favour of using geographical indications to protect Indigenous traditional knowledge, ${ }^{19}$ there have also been a number of more specific explanations in favour of protection. One of these is that geographic indicators provide a means of protecting traditional knowledge (in the strict sense of the word). Indeed, one of the features of many of the regimes used to protect geographical indications of origin is that they reward traditional cultural values and knowledge rather than promoting innovation per se, as is the case with most of the other forms of intellectual property ${ }^{20}$. Given the emphasis on the preservation and protection of localised traditional values, there is an obvious synergy between the law of geographic indications and traditional knowledge. As one commentator noted, geographical indications accords with the 'emphasis that indigenous communities typically place upon their traditional ways of life, including their relationship with their ancestors land, waters, and living ecosystems'. ${ }^{21}$ There is also a belief that Indigenous peoples and the owners of geographical indications share a common concern with the protection of the environment. Another related reason for the growing interest in geographical indications as a means of protecting traditional knowledge flows from the role that they both play in symbolizing quality and guaranteeing authenticity (and all the problems that accompany it). ${ }^{22}$

Another reason why geographical indications are thought to be particularly well suited to Indigenous knowledge is because there are no limitations on the period of protection. The fact that the legal rights remain in force as long as the collective tradition is maintained has obvious benefits for traditional knowledge. ${ }^{23}$ Another argument in favour of using geographical indications to protect traditional knowledge is that unlike most other intellectual property rights,

\footnotetext{
${ }^{19}$ David Downes, 'How Intellectual Property Could be a Tool to protect traditional knowledge' (2000) 25 Columbia Journal of Environmental Law 253, 268. C. Bramley and JF Kirsten, 'Exploring the Economic Rationale for Protecting Geographical Indicators in Agriculture' (2007) 46(1) Agrekon 47.

${ }^{20}$ C. Bramley and J.F. Kirsten, 'Exploring the Economic Rationale for Protecting Geographical Indicators in Agriculture' (2007) 46(1) Agrekon 47. It is important to note that GIs do not offer direct content (i.e. product or process) protection. See S. Frankel, 'The Mismatch of Geographical Indications and Innovative Traditional Knowledge (2011) 29(3) Prometheus 253.

21 David Downes, 'How Intellectual Property Could be a Tool to protect traditional knowledge' (2000) 25 Columbia Journal of Environmental Law 253, 272.

22 Kal Raustiala and Stephen Munzer, 'The Global Struggle over Geographical Indications' (2007) 18(2) The European Journal of International Law 337, 346. Oskari Rovamo, 'Monopolising Names? The Protection of Geographical Indications in the European Community' (2006) Helsinki University, Pro Gradu Thesis, 14; David Downes, 'How Intellectual Property Could be a Tool to protect traditional knowledge' (2000) 25 Columbia Journal of Environmental Law 253, 269 (Both 'protect and reward traditions while allowing evolution').

23 Shivani Singhal, 'Geographical Indications and traditional knowledge' (2008) 3(11) Journal of Intellectual Property Law and Practice 732, 733; David Downes, 'How Intellectual Property Could be a Tool to protect traditional knowledge' (2000) 25 Columbia Journal of Environmental Law 253, 269; Kal Raustiala and Stephen Munzer, 'The Global Struggle over Geographical Indications' (2007) 18(2) The European Journal of International Law 337, 345.
} 
geographical indications of origin are not freely transferable: ${ }^{24}$ the rights remain connected to the group or collective that initiated the rights in the first place. This helps to ensure that knowledge, practices, and rituals remain with and under the control of the community. Another reason why geographical indications are thought to be particularly well suited to protect Indigenous knowledge is because they are able to accommodate group rights. ${ }^{25}$ In so doing they help to overcome one of the shortfalls of copyright and patent protection; namely, that they focus on the individual at the expense of broader collective interests. This is not the case, however, with geographical indications of origin, which tend to prioritise collective interests over those of the individual. ${ }^{26}$

Another advantage of using geographical indications to protect traditional knowledge is that it offers a way of ensuring that Indigenous law is incorporated into the legal regimes used to regulate Indigenous culture ${ }^{27}$. One of the consequences of the decentralised nature of the geographical indications system is that questions such as who is to count as an Indigenous person, what type of subject matter ought to be protected, and how and when that subject matter might be used by third parties do not have to be resolved in advance, in the abstract, or at a distance. Rather than being answered by centralised agencies, these questions are answered by the community or group that is seeking protection. In the same way in which collectives such as the Parma Ham Consortium set their own internal rules that dictate when and how the name of a product can be used, so too the use of geographical indicators to protect traditional knowledge means that indigenous customary law can be used to determine the extent to which local knowledge is protected. In so far as geographical indications of origin ensure that it is the community rather than outsiders who set the rules that govern traditional knowledge, this accords with the principal of self-determination, while recognising that such laws must articulate with broader frameworks. It also means that Indigenous law is able to evolve and change over time.

One of the most important reasons why geographical indications of origin are thought to be particularly well suited to protect traditional knowledge is because they provide a means of

24 David Downes, 'How Intellectual Property Could be a Tool to protect traditional knowledge' (2000) 25 Columbia Journal of Environmental Law 253, 269.

${ }^{25}$ While community or group interests play a prominent role in many Indigenous Communities, this does not mean that decisions within Indigenous communities are made collectively. cf Shivani Singhal, 'Geographical Indications and traditional knowledge’ (2008) 3(11) Journal of Intellectual Property Law and Practice 732, 733.

26 Kal Raustiala and Stephen Munzer, 'The Global Struggle over Geographical Indications' (2007) 18(2) The European Journal of International Law 337, 345.

27 See E. Daes, 'Defending Indigenous peoples heritage' (Feb 2000) cited in Composite Study on the Protection of Traditional Knowledge, WIPO/GRTKF/IC/5/8 (28 April 2003), 42, para 105. 
recognising the connection to 'place' or 'country' that is so important for many Indigenous communities. This occurs because many of the regimes used to protect geographical indications of origin are based upon the idea that the protected product is an embodiment of the location that it originates from. This manifests itself in the requirement that applicants for geographical indications of origin must show a connection between the named product and the place where the product originates. In extreme situations, it is necessary to show that the product is 'an inimitable reflection of its geography'. ${ }^{28}$ The idea that certain products are intrinsically shaped by the location where they are grown is reflected in the notion of terroir, the French concept used to describe the characteristics or attributes of a place, resulting from the land, soil, geography, climate, human and seasonal influences which contribute to the unique characteristics of agricultural products (usually wine). ${ }^{29}$ Terroir is similar to the Aboriginal idea of connection to place in so far as it emphasises the relationship between human cultures, land and environment, ${ }^{30}$ as well as the spiritual value of that relationship. ${ }^{31}$ For some Indigenous communities, the connection to place arises because 'the land is the source of value and meaning, of rights and obligations ... The landscape is the source of meaning and value and the repository of history and events and can be read as a map of itself and its own creation'. ${ }^{32}$

Given the various points of connection between geographical indications of origin and traditional knowledge, it is not surprising that geographical indications are being looked upon as a possible legal mechanism to support and promote indigenous interests. Despite the attention given to this topic, there have been relatively few success stories to date. While it is possible to imagine geographical indications of origin being used to protect aspects of Indigenous

\footnotetext{
28 Oskari Rovamo, 'Monopolising Names? The Protection of Geographical Indications in the European Community' (2006) Helsinki University, Pro Gradu Thesis, 8.

29 Terroir refers to an 'area or terrain, usually small, whose soil and microclimate impart distinctive qualities to food products'. Elizabeth Barham, 'Translating terroir: the global challenge of French AOC Labelling' (2003) 19 Journal of Rural Studies 127, 130.

30 David Downes, 'How Intellectual Property Could be a Tool to protect traditional knowledge' (2000) 25 Columbia Journal of Environmental Law 253, 269.

31 'Beyond the measurable ecosystem there is an additional dimension - the spiritual aspect that recognises the joys, the heartbreaks, the pride, the sweat, and the frustrations of history'. Elizabeth Barham, 'Translating terroir: the global challenge of French AOC Labeling’ (2003) 19 Journal of Rural Studies 127, 131 (citing James E. Wilson, Terroir: The Role of Geology, Climate and Culture in the Making of French Wines (1988), 55). See also 'Oskari Rovamo, 'Monopolising Names? The Protection of Geographical Indications in the European Community' (2006) Helsinki University, Pro Gradu Thesis, 8.

32 David Turbull, Masons, Tricksters and Cartographers: Comparative Studies in the Sociology of Scientific and Indigenous Knowledge (Harwood Academic Publishers, 2000), 34. 'Everywhere is sacred since all the land was created in the Dreaming by the activities of Ancestral Beings as they moved across the landscape. These journeys left dreaming tracks, knowledge of which is recreated in song, story, and ceremony. Everyone has spiritual linkage to the land by virtue of birth such that they are the land. Knowledge of the Dreaming tracks, or the activities that created the land of one's birth, is therefore evidence of possession of the land and by the land'. Ibid.
} 
knowledge, ${ }^{33}$ there are a number of questions that need to be explored before we would be in a position to reach a conclusion about whether or not GIs could be used to provide effective protection for traditional knowledge. One of the most important is whether, despite the similarities, geographical indications of origin are able to accommodate traditional knowledge on its own terms or whether, as happens so often, Indigenous interests must be modified to comply with the requisite legal requirements.

One of the primary reasons why geographical indications of origin are touted as an appropriate way of protecting Indigenous traditional knowledge is because they recognise connection to place. While there are obvious parallels between geographical indications and traditional knowledge, this does not necessarily mean that the law is in a position whereby it can capture the symbiotic relationship that exists between Indigenous communities and land. Although from an Indigenous perspective a product may be inextricably linked to and shaped by country and dreaming, one question that needs to be considered is whether this can be translated into a legal framework. In a legal context how would you show, for example, the necessary connection between a dreaming story, country, a particular plant that grows on that country, and the product derived from that plant? Here we encounter the type of problem that sometimes arises with terroir: namely, the problem of how to prove the link between product and place. In part, this arises because of the belief that 'finding a link between a product and a terroir should, in principle, be scientifically demonstrable'. ${ }^{34}$ This scientific model of geographical indications of origin leads to the argument that as there is no exact knowledge of how geographical factors affect the product ${ }^{35}$ it is very difficult, if not impossible, to show scientifically that a particular product was shaped by the place where it originates ${ }^{36}$. This has led commentators to ask:

\footnotetext{
33 There are a number of problems that would have to be overcome before geographical indications of origin could be used as a form of protection. In Australia, for example, there would have to be a dramatic change of heart by policy makers who see geographical indications of origin as a new form of European colonisation. Given that the objects and knowledge that would be protected under these regimes may span a number of different Indigenous Communities, it would also be necessary for Communities to decide who has authority to negotiate and how benefits are to be shared.

34 Elizabeth Barham, 'Translating terroir: the global challenge of French AOC Labeling' (2003) 19 Journal of Rural Studies 127, 136. Oskari Rovamo, 'Monopolising Names? The Protection of Geographical Indications in the European Community' (2006) Helsinki University, Pro Gradu Thesis, 38. ('PDOs are based on the romantic core idea of terroir').

35 Oskari Rovamo, 'Monopolising Names? The Protection of Geographical Indications in the European Community' (2006) Helsinki University, Pro Gradu Thesis, 42. 'The minimum requirement is nevertheless that the particular climatic, geographical and morphological conditions which are claimed to affect the characteristics of the products are present throughout the geographical area concerned'.

${ }^{36}$ The 'requirement of an express link between the product and its geographical origin would preclude protection for many geographical names because a lack of scientific evidence on how the different elements of the specification affect the product. Also, if modern production techniques enable almost any product to be replicated anywhere, the geographical origin cannot be necessary for the quality and characteristics of the product'. Oskari Rovamo,
} 
'Could a product with exactly the same characteristics be produced in a different locality? Different products reflect their environments to greater or lesser degree and four components normally included in appellation systems (variety or species, yield, production methods, processing methods) also have varying degrees of influence for each product. For most agricultural products it is very difficult to trace specific attributes (such as trace elements in the soil) of local environments through to the crop of animal that originates there and even more difficult if the product is processed ${ }^{37}$.

To require as a precondition for protection scientific proof that the defining characteristics of a product are attributable to its geographic origin calls into question the very idea of natural geographical indications of origin ${ }^{38}$. It also creates a barrier to the suggestion that geographical indications of origin could be used to protect traditional knowledge.

There are a number of possible responses to this problem ${ }^{39}$. One response is to denaturalise geographical indications of origin. Instead of seeing the connection between product and place as a natural connection, it is possible to highlight the role that humans play in shaping that natural connection $^{40}$. This is reflected in the comment, that draws upon the opinion of Advocate General Colomer in the Feta litigation before the European Court of Justice, that 'the determination of the essential or exclusive link between the product and its terroir is not based on strict or exact science but on a global evaluation of all factors from climate to the flora and from the fauna to the people ${ }^{41}$. It is also possible to highlight the role that geographical indications play in helping to establish and sustain the very things that they are supposed to be based upon:

\footnotetext{
'Monopolising Names? The Protection of Geographical Indications in the European Community' (2006) Helsinki University, Pro Gradu Thesis, 42.

37 Warren Moran, 'Rural Space as Intellectual Property’ (May 1993) 12(3) Political Geography 263, 267.

38 Ibid, 266.

39 Another relevant development, which is not discussed here, is the increased attention being to given to historical links between product and place (particularly notable in relation to PGIs).

40 In part this builds upon the idea that 'because nature does not speak for itself but rather through the "translation" that is the production process' ... 'the legitimation process, to be effective, must be carried out not only within the territory of production but nested within multiple levels of coordination from the local to the global. In addition, the consumer's acceptance of the product must also be legitimated, which gives the word "quality" its full meaning'. Elizabeth Barham, 'Translating terroir: the global challenge of French AOC Labeling' (2003) 19 Journal of Rural Studies 127, 130.

41 Oskari Rovamo, 'Monopolising Names? The Protection of Geographical Indications in the European Community' (2006) Helsinki University, Pro Gradu Thesis, 42. This was based on Federal Republic of Germany and Kingdom of Denmark v. Commission of the European Communities, Joined Cases C456/02 and C466/02, Opinion of AG Colomer, delivered on 10 May 2005, para 194-96.
} 
namely, the uniqueness of the natural connection between product and place. ${ }^{42}$ This somewhat counterintuitive argument builds upon the fact that as the law of geographical indications provides that a protected name can only be used in relation to products from the designated territory, it helps to ensure that the named product is unique to that territory. Another possible response to the suggestion that natural geographic indications of origin are unsustainable because they are unable to be proven scientifically is to challenge the assumptions on which it is based: namely, that the connection between product and place needs to be judged according to scientific criteria. A useful starting point for doing this is to compare the process of naming geographical indicators with the scientific naming of plants.

The taxonomic process of naming a new plant variety is, as with the naming of a geographical indication, a complex and sophisticated process. Botanical taxonomy consists of three related activities; identification (referring a plant to a previously classified and named group), classification (ordering plants into groups based on perceived similarities and differences), and nomenclature (naming groups of plants according to rules developed for the process) ${ }^{43}$. The classificatory scheme used by taxonomists consists of a hierarchical series of categories that operate, in effect, like a 'boxwithin-a box ${ }^{44}$. Under this scheme, the basic hierarchy of the plant world is divided, in descending order, into Divisions; Classes; Orders; Families, Genera (genus), Species, and Varieties ${ }^{45}$. The process of placing plants into the appropriate taxonomic category requires taxonomists to order plants into groups based on perceived similarities and differences ${ }^{46}$. Since the time of Linnaeus, taxonomists have focused on morphological or physical similarities and differences as the basis on which plants are distinguished and thus classified.

The key rule for naming a plant is the requirement that the name has to be validly published. ${ }^{47}$ For this to occur, a name of a taxon must appear in Latin in a recognised scientific publication ${ }^{48}$. Each

\footnotetext{
42 On the constitutive role of GI regimes, which reinforce and authorise narratives that develop group identities around place-based distinction, see Matteo Ferrari. 'The Narratives of GIs' (Paper Presented at the International Society for the History and Theory of Intellectual Property, London 2012).

43 Judith Winston, Describing species: practical taxonomic procedures for biologists (New York 1999), 9.

44 J. McNeill, "Nomenclature of Cultivated Plants: A Historical Botanical Standpoint" (2004) 634 Acta Horticulturae 29,31

45 While all of these categories are important, the species plays a special role in that it acts as "the empirical or basic unit of classification". C. Jeffrey, An Introduction to Plant Taxonomy (London 1968), 17.

${ }^{46}$ For many years taxonomic novelty was a subjective process: what was new for one collector or botanical garden was not the same for another. While private collectors and gardens still operate in this manner, one of the triumphs of the International Code was that it introduced the idea of absolute (world-wide) novelty.

47 While a name may be validly published, it will only become the name by which a plant is known when it is accepted and used by botanists. there is no agency to enforce them Judith Winston, Describing species: practical taxonomic procedures for biologists (New York 1999), 9. If a plant has two names, the name which is valid is the earliest one to be published (after 1753) Alphonse de Candolle began to advocate for the application of the priority principle in the middle of the
} 
species must also be given a binomial name: the first word of each binomial is the name of the genus to which the species belongs (common noun) and the second word is a specific (trivial) epithet (adjective or possessive noun) ${ }^{49}$. Thus, the scientific name for the Bramley apple is Malus Domestica 'Bramley's seedling'. The publication contains descriptive information including the botanical name of the plant, where and when the plant was discovered, and the name of the discoverer. ${ }^{50}$ Another important principal that underpins the naming of plants is the use of the "type method', which ensures that a botanical name is permanently attached to its nomenclatural type, which is the element on which the description validating the publication of a name is based. ${ }^{51}$ The type acts as an artificial reference point that helps to determine how the name is to be used in the future $^{52}$. The type is a nomenclatural device that fixes a botanical name to a particular taxon. It does this by requiring taxonomists to attach a name for a new species to a single individual representing that species, the so-called type specimen ${ }^{53}$. For a name to be valid, the publication must include the name of the type and the institution where the type is deposited ${ }^{54}$. These rules and procedures, which are accepted and applied by botanist around the world, ensure that botanical names are unique, stable and used universally. They also ensure that a botanical name only refers to one plant and that the name is unique to that 'particular plant the world over'. In so doing, taxonomy ensures that botanical names operate as generic names: they are the name by which a plant species is known, at least by those professionals who commonly work with plants.

nineteenth century. This was adopted at the 1867 International Botanical Congress in Paris, and has remained a component of all subsequent botanical codes.

${ }^{48}$ International Code for Botanical Plant Nomenclature (2000), Art. 32.1(a). (Publication is effected, under this Code, only by distribution of printed matter (through sale, exchange, or gift) to the general public or at least to botanical institutions with libraries accessible to botanists generally. It is not effected by communication of new names at a public meeting, by the placing of names in collections or gardens open to the public, by the issue of microfilm made from manuscripts, typescripts or other unpublished material, by publication online, or by dissemination of distributable electronic media').

49 International Code for Botanical Plant Nomenclature (2000), Art. 23.1. 'The name of a species is a binary combination consisting of the name of the genus followed by a single specific epithet in the form of an adjective, a noun in the genitive, or a word in apposition, or several words, but not a phrase name of one or more descriptive nouns and associated adjectives in the ablative (see Art. 23.6(a)), nor certain other irregularly formed designations (see Art. 23.6(c)). If an epithet consists of two or more words, these are to be united or hyphenated. An epithet not so joined when originally published is not to be rejected but, when used, is to be united or hyphenated, as specified in Art. 60.9'.

${ }^{50}$ It will also include ecological information such as distribution, habitat preference, reproductive season, seasonal changes and so on. The description will also include the main taxonomic traits of the plant and a 'diagnosis' that highlights the 'distinctive morphological features' that distinguishes the plant from taxonomically related plants. International Code of Botanical Nomenclature (2000), Art. 32.2.

51 Clive Stace, Plant Taxonomy and Biosystematics (2nd ed., New York 1989), 213.

52 The type method has been described by taxonomists as 'as a legal device to provide the correct name for a taxon'. Samuel Jones and Arlene Luchsinger, Plant Systematics (2nd ed., New York 1986), 45.

${ }^{53}$ For the name of a species, the type is a physical specimen lodged in an herbarium or, in certain cases, a drawing of the plant.

54 International Code of Botanical Nomenclature (2000), Art. 37- 38. David Gledhill, The Names of Plants (3 ${ }^{\text {rd }}$ ed.) (Cambridge 2002), 27. 
There are a number of points of similarity and connection between geographical indications of origin and the names given to botanical varieties. In taxonomic terms, plant-based geographical indications not only tend to operate at the level of the variety, they also often take a form that is similar to their botanical equivalents ${ }^{55}$. In many cases, geographical indications will begin with the (scientific) species name of the plant in question. This is followed by an explanation of why, despite the similarities that the geographical indication shares with other 'plants' of that species, it differs from that broad class of products. For example, the PDO application for the Chinese Graperfruit (or pomelo) 'Guanxi Mi You' begins with the generic species name -- Citrus grandis -and its key characteristics ${ }^{56}$. The remainder of the application attempts to show how the named product exhibits traits that are a product of the place where it is grown that distinguish it from other plants of that species. In the case of Guanxi Mi You, the specificity is attributable to the unique climate and ecology of the area where the fruit is grown. As the application states, the 'hills, plains, paddy fields and eyots below 500 metres in altitude in 16 [named] towns in Pinghe County' in Fujian Province ${ }^{57}$ has certain geographical characteristics which ensures that the Citrus grandis have a 'unique sweet-and-sour flavour' ${ }^{58}$ In taxonomic terms, what this application is attempting to establish is, in effect, a specific new variety: 'Citrus grandis, Guanxi Mi You': which is, in effect, a new type of legal- scientific name. One of the consequences of including botanical names in many of the applications that underpin geographical indications is that it means that these geographical indications of origin are inextricably tied to the taxonomic and nomenclatural processes that generate and sustain botanical names. ${ }^{59}$ In so far as botanical names are used in geographical indications, it means that the legal rights are linked to the deposited type and the accompanying description that are linked to the scientific name. The specificity of the botanical name and the detailed rules and procedures that accompany it not only help to identify the named plant, they also help to stabilize that name and the associated description. They also help to define and demarcate the things to which the geographical indicator is attached (and thus where and how the name can properly be used). The inclusion of a scientific (botanical) name in a GI not only creates a high degree of certainty about the types of things which the GI (legally) signifies (which is in contrast to trade mark law's looser association

\footnotetext{
55 A variety is a specific sub-set of a species that exhibits the defining characteristics of the species (which in turn exhibits the defining characteristics of the genus). At the same time, a variety also shows a new trait that is not shared by other members of the species such as early flowering, larger fruit, or better flavour.

56 Official Journal of the European Union (24-9-2010) C 257/3, para 3.2.

57 Ibid, para 4.

58 Ibid, para 5.3

59 While the connection may not be as direct, taxonomic practices also play a role for GIs that are not based on plant materials. This is particularly the case for animal based products that build on zoological taxonomy and nomenclature.
} 
between the name and the things that they are connected to), it is-also means that plant based GIs can be seen as types of legal-biological hybrids.

While geographical indications may share many points in common with botanical names, there are also a number of important differences. One of these is that while many geographical indications of origin may draw upon and embody aspects of botanical nomenclature and taxonomy, a geographical indicator is not itself a botanical or scientific name: it is a legal name (or at least a hybrid name that is both legal and scientific) ${ }^{60}$. Another difference between botanical names and geographical indications is that the legal process is more administrative and less consensual than its scientific equivalent: decisions about the validity of a geographical indication are not made by peers but by way of administrative and legal mechanisms. Another difference is that while botanical names are universally accepted and used ${ }^{61}$, geographical indications are limited to the jurisdictions in which they are recognised. Another important difference relates to the criteria that are used to differentiate and individualise the plant or product in question. While with a botanical variety, the cause (or 'author') of the distinguishing trait may be known (it may be the result, for example, of cross breeding), this does not play a role in establishing the new name. This is in contrast to geographical indications where the specific traits that are used to individualise the species must be traced to the nominated geographical area.

Another important difference between geographical indications of origin and botanical names relates to the nature of the name and what it represents. As we mentioned above, once a botanical name is accepted by the scientific community it becomes unique to that "particular plant the world over'. While geographical indicators are also unique, there are subtle and important differences in what this means. The reason for this is that naturalised geographical indications not only provide the product (variety) with the traits that allow it to be differentiated from the class of products to which it belongs (species), they also go one step further and make the claim that the individualising traits are unique to the geographical area named in the application ${ }^{62}$. While the uniqueness of a botanical name is manufactured (via the complex system of publication, description and type specimen that underpins botanical nomenclature), the

\footnotetext{
${ }^{60}$ Given that geographical indications typically embody botanical names and the taxonomic practices that sustain them, it is perhaps better to think of them as hybrid names that are at once legal and scientific: the relative influence of each depending on the product in question. Other non-legal, non-scientific factors add to this hybridity.

61 The universal use of scientific names tends, however, to be limited to experts.

${ }^{62}$ While the botanical variety is tied to the deposited type (that is named in the publication in which the new plant variety is christened), there is nothing inherent in the location where the type is stored.
} 
uniqueness of a natural geographical indication is meant to be a result of the place where the named product originates ${ }^{63}$. (It is possible to rethink less-natural focused GIs in similar terms).

The role that the uniqueness of the name plays within botany also differs from the role it plays in law. The unique and standardised nature of the botanical name ensures that the name is able to operate as common currency that underpins and sustains scientific research. Uniqueness performs a number of different functions in the legal grant of a geographical indication of origin. One of the most important is that it enables the law to work on the assumption that there cannot be a product from a different place with the same qualities as the protected product. This in turn enables it to be assumed that the use of a protected name on a product that is not from the specified location is necessarily misleading. This is reflected in the idea that the 'fundamental concept behind GIs is that specific geographical locations yield product qualities that cannot be replicated elsewhere. Because the place is said to be essential to the product, proponents argue that products outside a specified region cannot be permitted to use its place name in marketing and on product labels'. ${ }^{64}$ By limiting protection to products that have traits that are unique to a particular geographic area, this also means that third parties from outside the geographical area are unable to argue that the grant of a legal right means that something of theirs has been taken away. ${ }^{65}$

In part, the criticism made of terroir, nature-based geographic indications of origin and, by inference, GI protection for Indigenous knowledge is that it is not possible to establish the uniqueness that is assumed to underpin the grant of the legal right. The criticism here is not that geography and environment do not impact upon the products that are derived from the place in question, so much as that it is not possible to show that the requisite qualities are unique to that geographical area ${ }^{66}$ In the case of champagne, for example, there is dissension over some of the

\footnotetext{
63 On this see Warren Moran, 'Rural Space as Intellectual Property' (May 1993) 12(3) Political Geography 263, 276.

${ }^{64} \mathrm{Kal}$ Raustiala and Stephen Munzer, 'The Global Struggle over Geographical Indications' (2007) 18(2) The European Journal of International Law 337, 338.

${ }^{65}$ Winemakers are often 'striving to produce a wine that is special in the sense that it bears the "signature" of their style of vinification'. Elizabeth Barham, 'Translating terroir: the global challenge of French AOC Labeling' (2003) 19 Journal of Rural Studies 127, 131 (a 'GI-dominated product is not simply from a place; it is said to have unusual, even unique qualities that the place alone can provide'). Kal Raustiala and Stephen Munzer, 'The Global Struggle over Geographical Indications' (2007) 18(2) The European Journal of International Law 337, 344 ('food and beverages that evoke the term terroir have signature qualities').

66 'The lack of scientific evidence about what the terroir inputs actually do' means that it is far from clear that a product's characteristics derived from geography' are exclusive. Suggestion that any 'one natural aspect of a region can also be found somewhere else'. Oskari Rovamo, 'Monopolising Names? The Protection of Geographical Indications in the European Community' (2006) Helsinki University, Pro Gradu Thesis, 8. See also Justin Hughes, 'Champagne, Feta, and Bourbon: The Spirited Debate over Geographical Indications' (2006) 58 Hastings Law Journal 299.
} 
assumptions made about the influence of geography on the resulting wines ${ }^{67}$. This is reflected in the comment that there are many environments where the 'exclusive' product could be replicated and that methode champenoise 'could be considered to be much more important that the physical environment which produces Pinot Noir and Chardonnay grapes of high acidity' ${ }^{68}$. Such arguments lead to the conclusion that 'many geographical indications would [now] be precluded from protection because modern techniques enable us to replicate and produce almost any product anywhere'. ${ }^{69}$

If we acknowledge the role that humans (and history) play in shaping the connection between product and place, geographical indications of origin quickly change and with them the rationales, arguments and what is expected of them. For example, it has been suggested that the ambiguity as to whether geographical indications refer solely to fixed natural features or also to (moveable) human skills has 'major implications for the normative justifications of GIs, as well as the questions of who can legitimately use the GI and who cannot'. ${ }^{70}$ It also means that 'GIs function as something else than a combination of the origin and quality functions. This might also explain why modern geographical indications law seems to be moving away from the idea of terroir and afford protection to GIs solely on the basis of a certain reputation among consumers'. ${ }^{71}$ One of the consequences of recognising the role that humans play in shaping the connection between product and place is that it means that even the purest of natural geographic indications of origin are built upon artificial, non-natural, legal factors. This, in turn, means that the connection between place and product is not something that can or should be judged exclusively on scientific terms ${ }^{72}$.

To accept that connection to place is not something that should be exclusively judged on scientific terms opens the way for the protection of Indigenous traditional knowledge. The problem with this, however, is that it begs the question of whether the law of geographical

\footnotetext{
67 Warren Moran, 'Rural Space as Intellectual Property’ (May 1993) 12(3) Political Geography 263, 267.

68 Ibid.

69 Oskari Rovamo, 'Monopolising Names? The Protection of Geographical Indications in the European Community' (2006) Helsinki University, Pro Gradu Thesis, 9.

70 Kal Raustiala and Stephen Munzer, 'The Global Struggle about Geographical Indications' (2007) 18(2) The European Journal of International Law 337, 343.

71 Oskari Rovamo, 'Monopolising Names? The Protection of Geographical Indications in the European Community' (2006) Helsinki University, Pro Gradu Thesis, 9. See Teshager Dagne, 'Harnessing the Development Potentials of Geographical Indications with respect to Traditional knowledge based agricultural products' (2010) 5(6) Journal of Intellectual Property Law \& Practice 441.

${ }_{72}$ This is reflected in the gradual extension of GIs away from wine to cheese to crafts, textiles, toys and other nonagricultural products.
} 
indications of origin, even in a modified denaturalised form, would ever be able to accommodate Indigenous traditional knowledge on its own terms. In this sense it goes to the heart of the question we posed at the outset: namely, is it realistic to expect that geographical indications of origin can be used to protect Indigenous knowledge? The problem here is not that we are operating in the words of the Australian High Court at 'the intersection between two normative systems, ${ }^{73}$ so much as that we are bringing together two very different ways of thinking about the world. The problem confronting Indigenous communities hoping to use geographical indications of origin to protect traditional knowledge is not so much in terms of the substantive legal rules (although the doctrinal rules may cause some problems). Rather, the problems of accommodation arise in relation to the various techniques that are used to overcome the fundamentally local and defeasible character of geographical indications, as well as the shared agreements that underpin and sustain those techniques. More specifically, the problems arise because many of the practices, concepts, rules and procedures that underpin and sustain the substantive law were formulated within a framework that is at odds with Indigenous interests. While aspects of the law of geographical indications of origins are pre-modern, particularly in terms of the form that the law takes, in other respects, however, the law is very modern. This is particularly the case in relation to the non-doctrinal aspects of the law: that is, the adjectival and performative aspects of the law of geographical indications. ${ }^{74}$

While the rationalist tradition of evidence that underpins the law of geographical indications operates on the basis that 'evidence is something that testifies to the external real world of facts', in contrast 'evidence about traditional knowledge is itself evidence of a different way of knowing. ${ }^{75}$ This difference manifests itself in a number of ways ${ }^{76}$. While the evidential system that underpins intellectual property law assumes that knowledge and information are, for the most part, public goods accessible to all, in contrast 'the accessibility of knowledge in Aboriginal cultures [is often] highly selective and dependent on age sex, and spiritual affiliation. Details of "connection to place", which are needed to establish geographical indications of origin, 'are the very ones most likely to be highly secret'. ${ }^{77}$ Another important difference relates to the

\footnotetext{
73 Members of the Yorta Yorta Aboriginal Community v Victoria (2002) 194 ALR 538, 550 (Gleeson CJ, Gummow and Hayne JJ).

74 In most cases, these issues are not usually considered. One notable exception is in relation to the scientific model of geographical indications of origin, which effectively asks us to consider: how do you prove the connection between product and place?

${ }^{75} \mathrm{~K}$. Anker, 'The truth in painting: cultural artefacts as proof of native title' (2005) 9(1) Law, Text, Culture 91, 92.

${ }^{76}$ The approach taken by the law of geographical indications of origin is at odds with the approach taken by Indigenous communities on a range of other matters including how geographical boundaries are drawn, and how products are categorised and named.

${ }_{77}$ K. Anker, 'The truth in painting: cultural artefacts as proof of native title' (2005) 9(1) Law, Text, Culture 91, 97.
} 
transportability of evidence. While intellectual property law presumes that witnesses are able to give evidence away from the place where the evidence was generated and also that the place where the testimony is given is irrelevant, this may not be the case with Indigenous witnesses whose 'ability and authority to speak about certain places literally depends on them being physically present'. ${ }^{78}$ The reason why the context where a testimony is delivered may be important for an Indigenous witness is because there is a 'metonymic association between following the law, walking the country and doing ceremony such as singing, dancing or painting the country. Evidence ... is often given in "on country" hearings in recognition of the inability of some claimants to speak about country without it being beneath their feet ${ }^{79}$. Another point of difference between the evidential scheme used by the law of geographic indications and the type of evidence that might be preferred by Indigenous communities relates to how connection to place is proved. Although the evidence used to prove connection to place (or the boundaries of a would-be geographic area) takes different forms depending on the geographical indication in question, it is united by the fact that it confirms to certain unstated and shared presumptions about the type of evidence that will and will not be taken into account when deciding doctrinal issues such as proving connection to place. While scientific evidence that the distinguishing characteristics of a named product is directly (and uniquely) shaped by the geographic location where it is grown or produced or historical evidence about a product's longstanding association with a particular location are clearly relevant, this is in marked contrast to the evidence that might be given by an Indigenous community. For example, paintings, or at least certain types of paintings, are used by Indigenous communities in Australia as a way of communicating connection to country to non-Aboriginal people and to the courts. ${ }^{80}$ This occurs because paintings make a 'normative claim about the basis for entitlement and the manner in which it can be proved'. ${ }^{81}$ As Anker notes:

"the "tradition" of design, boundaries and Dreaming stories is the frame of reference which give a painting value as evidence. Designs originating in sand, rock, bark, and body painting embody relationships between ancestors and law, living people and places in the land, which makes them crucially relevant to what is being translated ... as property

\footnotetext{
78 Ibid, 113.

79 Ibid, 98.

80 As Ngarralj Tommy May said of Ngurrara Canvas II, a painting he produced with around 50 artists as part of a native title claim: 'The painting is only for proof. Maybe the [white people] will say "we don't believe you" ... That's why we made this painting, for evidence. We have painted our story for native title people, as proof. We want them to understand, so that they know about our painting, our country, our ngurrara. They are all the same thing'; as cited in K. Anker, 'The truth in painting: cultural artefacts as proof of native title' (2005) 9(1) Law, Text, Culture 91, 92.

81 Ibid, 93.
} 
rights. In evidence, the painting illustrates the rights (such as those indicated by boundaries), the origin of those rights in a system of law (such as Dreaming stories) and facilitates the oral evidence of the witnesses ${ }^{92}$.

As it stands, it is highly unlikely that custodians of traditional knowledge would be able to use the existing rules of evidence to prove connection to place in a way that would accord with Indigenous ideas about evidence and proof. The problem for Indigenous communities is that connection to place is very difficult if not impossible to prove without recourse to materials that would be inadmissible under the traditional rules of evidence. ${ }^{83}$ One response to this situation is to argue that if Indigenous communities want to make use of geographical indications of origin, they need to comply with the existing rules and procedures. The problem with this is that it undermines one of the reasons why Indigenous communities might be attracted to geographical indications of origin in the first place, as well as the very thing that the law is supposed to be supporting: namely, the distinct and local aspects of traditional knowledge. In this situation, there is a choice as to whether the law is changed to allow traditional knowledge to be protected in a way that is sympathetic to Indigenous interests, or whether Indigenous peoples are subject 'to a deeper process of colonisation by reducing them to a singular unambiguous discourse known to the law'. ${ }^{84}$ Rather than asking whether we should be 'contemplating changes and adaptations to the intellectual property regime to render it more neutral (from an ethnocentric perspective' $)^{85}$, it would perhaps be better to contemplate changes that would ensure that the law of geographical indications was more culturally specific and biased. We can get a sense of the type of changes that would be needed to do this if we look to native title law in Australia, which has a number parallels with geographical indications: both apply to a specified geographical area and also require Indigenous communities to show a connection to place to establish the relevant legal rights ${ }^{86}$.

\footnotetext{
82 Ibid, 100.

83 Alex Reilly, 'The Ghost of Truganini: Use of Historical Evidence as Proof of Native Title' (2000) 28 Federal Law Review 453, 454.

84 Alex Reilly, 'Cartography and Native Title' (2003) 79 Journal of Australian Studies 1.

85 Daniel Gervais, 'Traditional Knowledge: are we closer to the answer(s)? The Potential role of Geographical Indications' (2009) 15:2 ILSA Journal of International and Comparative Law 551, 552.

86 Native title continues where there a connection with the land that has been substantially maintained by a community which acknowledges and observes, as far as practicable, laws and customs based on the traditional practices of its predecessors'. Alex Reilly, 'The Ghost of Truganini: Use of Historical Evidence as Proof of Native Title (2000) 28 Federal Law Review 453, 454.
} 
Native title was formally recognised in Australia in the 1992 High Court decision of Mabov Queensland (No 2) ${ }^{87}$. While this decision paved the way for the legal and political recognition of Indigenous interests in land in Australia, it quickly became clear that additional changes were needed if Indigenous interests were to be adequately protected. The reason for this was that there were 'unique questions of proof stemming from the sui generis nature of native title' which demanded a 'unique approach to the treatment of evidence which accords due weight to the perspective of aboriginal people ${ }^{88}$. A number of changes were made to allow Indigenous modes of evidence and proof to become part of the law of native title. One of the most important was in terms of how connection to place was proved. To this end, changes were made to allow songs, dances, stories, and paintings to be presented as evidence of customary law. Changes were also made to allow these non-traditional forms of evidence to be used to prove a communities' connection to a particular geographic area. ${ }^{89}$ There have also been changes in terms of the place where evidence is presented. Rather than asking or expecting indigenous people to travel to urban locations to give evidence, courts hearing native title claims sometimes travel to remote locations to hear evidence in country. This has been explained on the basis that 'for the Court to require indigenous people to travel perhaps thousands of kilometres to a place that they might not have been, to give evidence in a confined courtroom, to speak of Country in the abstract, to refer to maps without a context would ... offend the very notions of "access" and "justice". 90

The experience in relation to native title law in Australia shows that it is possible for a legal system to adapt to and accommodate traditional knowledge on, or at least partially on, its own terms ${ }^{91}$. The key question for our purposes, however, is whether it is realistic to expect that similar changes might also be made to the law of geographical indications? While it possible to imagine some changes being made that would make it easier for traditional knowledge to be

87 (1992) 175 CLR 1; [1992] HCA 23.

88 Alex Reilly, 'The Ghost of Truganini: Use of Historical Evidence as Proof of Native Title' (2000) 28 Federal Law Review 453, 467 citing Delgamunkw v British Columbia (1997) 153 DLR (4th) 193, 230. Procedures for proving Native Title have been 'modified to take account of cultural concerns of Indigenous claimants'. K. Anker, 'The truth in painting: cultural artefacts as proof of native title' (2005) 9(1) Law, Text, Culture 91, 97.

${ }^{89}$ Section 82(3) of the 1993 Native Title Act, as enacted, provided that 'The Court, in conducting proceedings, is not bound by technicalities, legal forms or rule of evidence'. This provision was amended in 1998 to state that the 'Federal Court is bound by the rules of evidence, except to the extent that the Court otherwise provides'. 1993 Native Title Act s 223(1).

${ }^{90}$ Louise Anderson, 'The Law and the Desert: Alternative Methods of Delivering Justice' (2003) 30(1) Journal of Law and Society 120, 130.

91 In many ways, the situation in relation to traditional knowledge and GIs is similar to the position of native title prior to the High Court decision of Mabo where the 'understanding of property rights as a question of measurement and administration contributed to the failure of the law to recognise Indigenous relationships to land in the first place'. The situation began to change with the High Court decision of Mabo, which required a 'reflection of epistemic and ontic commitments to place'. See Alex Reilly, 'Cartography, Property and the Aesthetics of Place: Mapping Native Title in Australia', in A. Kenyon and P. Rush (eds.), An Aesthetics of Law and Culture: Text, Images, Screens (2004) 221, 229. 
protected, it is highly unlikely that the law of geographical indications would ever accommodate Indigenous traditional knowledge in its various and distinct forms, at least in a manner that takes account of indigenous-style evidence. It is unlikely, for example, that the European Court of Justice would decamp to the deserts of Central Australia to hear evidence in relation to a dispute about the alleged misuse of an Australian Indigenous geographical indication of origin that occurred in Europe. In the same way in which proponents of global indigenous collecting societies would be unlikely to accept that the societies would be established anywhere but in 'global' centres such as Geneva, London, or Washington (but certainly not in Weipa), so too it is unlikely that disputes in relation to an Indigenous GI would be heard in country, as happens with native title. It is equally unlikely that non-Australian courts would allow a painting to be introduced into evidence as proof that a named 'product' was intrinsically linked to a specified geographical area. The alien and somewhat unsettling nature of this form of evidence is exacerbated by the fact that Indigenous paintings introduced as evidence of connection to place do not merely map out or represent connection to place: they are not 'something which points to knowledge about country and traditional law'. The reason for this is that 'the painting is the country', a 'painting is not just a fact about law, it is law'. ${ }^{92}$

Although Australian courts might be able to adapt to the evidential needs of Aboriginal and Torres Straight Islanders and Canadian courts might be able to accommodate the specific needs of Inuit peoples, it is not feasible to expect national courts or agencies who register geographical indications of origin to accommodate the evidential systems of the different Indigenous communities around the world who might want to make use of GI protection. The lack of ready access to knowledge and expertise about the distinct needs of indigenous peoples in other countries would not only make this impractical, it would also mean that there is less likely to be the political will needed to suspend the traditional rules of evidence. As the number of indigenous communities wanting to make use of GI protection increases, so too do the different models of evidence and proof and with it the chances of conflict and uncertainty. The conflicting and incommensurable epistemologies also means that it would be very difficult to modify existing international treaties to accommodate traditional knowledge, except in very abstract and unhelpful ways. Perhaps the most important reason why the adjectival dimensions of GI laws are unlikely to be changed to accommodate traditional knowledge in a way that was sympathetic to indigenous interests is because it would undermine the GI system. The reason for this is that geographical indications of origin are concerned with local knowledge, practices and products

${ }^{92} \mathrm{~K}$. Anker, 'The truth in painting: cultural artefacts as proof of native title' (2005) 9(1) Law, Text, Culture 91, 92. 
that are, almost by definition, diverse, complex, and fragmented. At the same time, for local products to become part of a global GI system, they need to be observed, noted, recorded and placed in a format that enables them to be moved from one site to another. Over time the law has developed a number of devices, techniques, rules, and procedures that allows this to occur. One of the problems with the idea of adapting the rules of evidence to accommodate traditional knowledge is that it would mean that local products placed into the global GI system would be accompanied by local systems of evidence and proof: a process which would undermine the mobility and thus the very possibility of geographical indications of origin.

The upshot of this is that traditional knowledge is only likely to be recognised and protected by geographical indications of origin to the extent that it complies with non-Indigenous modes of evidence and proof. ${ }^{93}$ While the GI system does offer the possibility of protecting aspects of traditional knowledge it will, it seems, inevitably be on non-Indigenous terms. This does not mean, however, that an unmodified GI system does not offer potential benefits to some indigenous communities. It does mean, however, that the protection would not be as sympathetic to indigenous interest as is often assumed. Given the costs involved in putting together a GI application and the relatively low level of benefits that are likely to flow from protection, it is necessary to ask whether it is worth it. Ultimately, this is a question for traditional owners to decide. Whatever decision is made, however, it seems that geographical indications do not, despite the similarities and points of connection, offer the panacea that many hope for.

93 For a discussion of these issues in another context see Alex Reilly, 'Cartography and Native Title' (2003) 79 Journal of Australian Studies 1. 